\title{
Moderna e virtuosa: gênero e nação na Turquia contemporânea*
}

\author{
Paula Sandrin** \\ Monique SochaczewskiGoldfeld***
}

\begin{abstract}
Resumo
O artigo propõe uma discussão sobre as imbricações entre gênero e nação na Turquia, analisando como diferentes projetos de nação mobilizam questões de gênero e produzem discursos acerca de feminilidades e masculinidades que influenciam políticas de gênero no país. Argumentamos que dicotomias rígidas entre projetos ditos 'progressistas' ou 'atrasados' não se sustentam, dado que as premissas de que corpos e comportamentos de mulheres devem ser regulados e que a restrição de liberdades e direitos pode ser justificada em nome da (des)igualdade de gênero e da (ausência ou excesso de) liberdade sexual são amplamente compartilhadas no país.
\end{abstract}

Palavras-chave: Gênero, Sexualidade, Nação, Turquia, Feminismos.

\footnotetext{
* Recebido em 19 de julho de 2019, aceito em 31 de julho de 2020.

${ }^{* *}$ Professora Adjunta, Instituito de Relações Internacionais (IRI/PUC-Rio), Rio de janeiro, RJ, Brasil. paulasandrin@hotmail.com / http://orcid.org/0000-0002-0295-4620

*** Professora do Mestrado em Direito, Justiça e Desenvolvimento do Instituto Brasileiro de Ensino, Desenvolvimento e Pesquisa (IDP), Brasília, DF, Brasil. moniquesgoldfeld@gmail.com / http://orcid.org/0000-0003-3758-6255
} 
Modern and Virtuous: Gender and Nation in Contemporary Turkey

\begin{abstract}
This article discusses imbrications between gender and nation in Turkey, analyzing how different nation-building projects mobilize gender issues and produce discourses about femininities and masculinities that influence gender policies in the country. We argue that rigid dichotomies between projects considered "progressive" or "backwards" cannot be sustained in the country, given the wide acceptance that women's bodies and behaviors must be regulated and that the restriction of rights and freedoms are justified in the name of gender (in)equality and (the absence or excess of) sexual freedom.
\end{abstract}

Keywords: Gender, Sexuality, Nation, Turkey, Feminisms. 


\section{Introdução}

Esse artigo propõe uma discussão sobre como diferentes projetos de consolidação da nação turca mobilizaram - e mobilizam - questões de gênero e envolvem processos de produção $e$ reprodução de discursos acerca de feminilidades e masculinidades que influenciam políticas de gênero no país. Desde a intensificação do processo de ocidentalização, modernização e secularização do país seguindo linhas europeias, com Mustafá Kemal Atatürk, entre 1923 e 1938, até a ascensão do Partido Justiça e Desenvolvimento (AKP, nas iniciais turcas), com raízes islamistas, a partir de 2002, o papel "adequado" a ser desempenhado pelas mulheres turcas vem sendo discutido e contestado, com efeitos simbólicos, materiais e psíquicos nas vidas dessas mulheres. Argumentamos, aqui, que é possível pensar a questão de gênero como um dos marcadores da(s) identidade(s) nacional(is) turca(s), mobilizada(s) de formas diversas por atores políticos turcos, que avançam diferentes projetos de nação. Ademais, discutiremos como tais projetos de nação não apenas constituem e distribuem determinadas masculinidades $e$ feminilidades, mas são constituídos por elas.

Apesar da crescente atenção concedida à história e questões correntes da Turquia por parte de acadêmicos sul-americanos, ou mesmo turcos, radicados no Cone Sul ${ }^{1}$, análises sobre questões de gênero na Turquia ainda são muito periféricas na região ${ }^{2}$. Acreditamos que explorar o caso turco é relevante, além do ineditismo, por ressaltar a complexidade religiosa e étnica do mundo muçulmano, ajudando a lançar luz sobre região que carrega preconceitos, em grande parte ligados a questões de gênero.

O governo do AKP é frequentemente acusado de promover discursos e práticas conservadores e religiosos (Güneş-Ayata; Doğangün, 2017) que não contribuem para diminuir a desigualdade de gênero e a violência contra mulheres e populações não heterossexuais no país. Propostas como a criminalização do adultério (Fisher Onar; Müftüler-Baç 2011) e discursos do Presidente Recep Tayyip Erdoğan- encorajando, por exemplo, mulheres a terem pelo menos três filhos (Daloglu, 2013), caracterizando mulheres que rejeitam a maternidade como "incompletas" $e$ "deficientes" (Turkish..., 2016) e o uso de contraceptivos como traição (Lowen, 2018) aprofundariam desigualdades e violências de gênero no país. De acordo com o índice de desigualdade de gênero de 2017 (Nações Unidas, 2018), a Turquia ocupa a 64 posição de um ranking que inclui 160 países e a participação das mulheres no mercado de trabalho é de $34 \%$, o que coloca a Turquia atrás de todos os países da OCDE e da maioria dos países em desenvolvimento. Além disso, estatísticas oficiais mostraram um aumento de $1.400 \%$ nos casos reportados de violência doméstica entre 2003 e 2010 (Lowen, 2018). Desde a tentativa de golpe frustrada em 2016, dezenas de ONGs de mulheres foram fechadas e marchas LGBTQIA+ banidas (Comissão Europeia, 2018).

O texto em questão buscará evidenciar como as imbricações complexas e matizadas entre gênero e nação em geral, e na Turquia contemporânea em particular, tornam pouco plausíveis divisões rígidas e bem demarcadas entre significantes como "modernidade" e "atraso", "secular" e "religioso", "liberdade" e "sujeição", "proteção" e "violência". Como veremos, as fronteiras entre projetos nacionais tidos como mais modernos e progressistas e projetos lidos como mais atrasados e

\footnotetext{
1 Guilherme Casarões (2016), Elena Lazarou e Milan Yan Nascimento (2016) em texto conjunto, assim como Marcos Aurélio Guedes de Oliveira e Deijenane Gomes dos Santos (2018) em artigo a quatro mãos, são autores de análises da chamada Declaração de Teerã. Nilufer Narlı e Leonardo Nelmy Trevisani (2016) dedicam-se às questões militares. Segâh Tekin (2016), Ekrem Eddy Güzeldere (2018) e Paula Sandrin (2015; 2014) debruçam-se sobre a política externa turca e também sobre suas relações com o Brasil e a União Europeia. Monique Sochaczewski (2018), por sua vez, traz a perspectiva histórica do Império Otomano à Turquia Contemporânea.

2 Tais questões foram abordadas de forma indireta na pesquisa da antropóloga Liza Dumovich (2018) que realizou etnografia dos seguidores do Movimento Gülen na América do Sul. Sua observação participante acabou restrita às casas das mulheres, espaço feminino nas casas das famílias, e sohbets (pequenos encontros comunitários), com acesso limitado aos homens porque, conforme declara, segregação de gênero é marca da configuração da comunidade em questão. Questões de gênero no país também apareceram em textos de jornalistas como Patrícia Campos Mello (2017) e Adriana Carranca sobre curdas. Ver, por exemplo, série de matérias publicadas por Adriana Carranca sobre as curdas para $O$ Globo em setembro de 2015 [https://oglobo.globo.com/mundo/mulheres-compoem-pelo-menos-40-das-tropas-do-pkk17616945 - acesso em: 13 jul. 2021].
} 
restritivos no que tange à questão de gênero (como o do AKP) são porosas. Ambos compartilham um enquadramento da posição das mulheres na sociedade como uma batalha pela alma do país e a ideia de que os corpos e os comportamentos das mulheres devem ser regulados, para que a própria nação, seja como ela for definida, sobreviva e não seja violada. Exploremos também como a (des)igualdade de gênero e a (ausência ou excesso de) liberdade sexual são frequentemente mobilizadas para legitimar intervenções e restrições de direitos e liberdades de determinados grupos sociais do país. Ademais, discutiremos como as diversas formas de resistências a esses entrelaçamentos entre nação e gênero na Turquia se chocam e se solidarizam em diferentes contextos.

De forma a atingir tais objetivos, dividiremos o artigo em quatro partes. A primeira seção apresenta considerações teóricas sobre as relações entre gênero e nação e discute como a relação entre esses dois termos pode ser pensada como uma via de mão dupla, na qual um constitui parcialmente o outro. A segunda, aborda o que chamamos de projeto dominante de nação turca $\left(\right.$ kemalista $^{3}$ ) e de que formas o gênero é por ele constituído e mobilizado e, ao mesmo tempo, o constitui. A terceira e a quarta seção exploram, por meio da história da piloto de combate Sabiha Gökçen, filha adotiva de Mustafa Kemal Atatürk, as violências autorizadas pelos entrelaçamentos complexos entre os marcadores de diferença gênero, nação, etnia e classe, e os limites impostos à igualdade e liberdade femininas no projeto nacional kemalista. Exploramos também nestas seções como a inserção da Turquia em um sistema internacional atravessado por concepções cambiantes e hierarquizadas de gênero e sexualidade generificou a própria nação turca de formas ambivalentes, ora como feminina, ora como hipermasculina, e como atores políticos kemalistas buscam responder à essa generificação. E, finalmente, busca-se mostrar que, assim como todos os projetos de nação sofreram e sofrem contestações, na Turquia não foi diferente. Lá subsistem outros projetos de nação, que avançam outras relações e concepções de gênero, e tentam se fazer ouvidos. Nesse sentido, menciona-se aqui brevemente as contestações advindas dos feminismos curdos e dos feminismos islâmicos $e$ as potenciais divergências e solidariedades entre esses grupos, cujas fronteiras não são intransponíveis nem estáticas.

\section{Considerações teóricas: os entrelaçamentos da nação e do gênero}

Sobre a nação, sabemos que se trata de uma comunidade política imaginada e limitada (Anderson, 2006), produzida e reproduzida por meio de práticas, de natureza simbólica ou ritual, que inventam tradições (Hobsbawm; Ranger, 2000) e que se constrói por meio de práticas discursivas e materiais que estabelecem fronteiras entre 'nós' e 'eles' e determinam quem pertence e quem não pertence, quem está dentro e quem está fora (Campbell, 1992). Também sabemos que a nação surgiu no fim do século XVIII e se consolidou a partir do século XIX como resultado de vários processos históricos, como a emergência do 'capitalismo impresso' - a impressão em massa de romances e jornais em línguas locais - e do Iluminismo (Anderson, 2006); as revoluções Francesa, de 1848 e Industrial; e a emergência do eleitorado de massa e movimentos trabalhistas (Hobsbawm, 2000) que desestabilizaram a ordem política e social anterior e suas tradicionais fontes de legitimidade, ou seja, a Igreja e o Direito Divino dos Reis. Tal vácuo foi ocupado pela nação, que se tornou uma nova fonte de legitimidade dos Estados. Ao forjar um senso de identificação da população com a nação, se legitimaria a autoridade daqueles que a representariam, simbolizariam $e$ expressariam.

Apesar de imaginada, inventada, construída, produzida e/ou performada; apesar de não contar com nenhuma essência ou status ontológico que lhe dê sustentação; nos é dito que a nação comanda legitimidade emocional profunda (Anderson, 2006) e lealdade e obediência de seus cidadãos (Hobsbawm, 2000, além de despertar e mobilizar paixões coletivas de forma tão intensa que algumas pessoas se prontificam a morrer em nome dela (Stavrakakis, 2007). Apesar de ser

\footnotetext{
3 Ressalta-se aqui que o termo vem do nome de Mustafá Kemal Atatürk, sendo, portanto, ligado ao projeto estabelecido no período de governo deste, de 1923 a 1938, envolvendo as chamadas "seis flechas" (altı ok): republicanismo, laicisismo, nacionalismo, populismo, estatismo e reformismo. Por vezes, aparece também na literatura como "atatürkismo" (Findley, 2010:258).
} 
produto de contextos e processos históricos específicos, sabemos que a nação, enquanto objeto de identificação e de investimentos afetivos, persiste até os dias atuais.

Por fim, aprendemos que essa persistência se dá porque a nação, similarmente às religiões, provê explicações para eventos contingentes e aleatórios; estabelece uma linha de continuidade entre um passado imemorial, o presente e o futuro; e promete estabilidade e fixidez às identidades, escondendo a contingência $e$ arbitrariedade que marcam nossa existência $e$ ausência de fundamentos de nossas identidades individuais e coletivas. Como bem colocado por Anderson (2006:12), "a mágica do nacionalismo é transformar o acaso em destino". Além disso, como salienta Hobsbawm (2000), a produção de uma continuidade histórica entre o passado, o presente e o futuro permite que o estado atual de coisas, que privilegia alguns em detrimento de muitos, pareça natural. Diferentes projetos de nação na Turquia valorizam e resgatam passados diversos: em um caso, um "autêntico" passado turco pré-islâmico; em outro, uma suposta "era de ouro" otomana. A disputa sobre qual passado deve ser glorificado tem efeitos no presente, inclusive no que concerne à questão de gênero, como discutiremos adiante.

Sobre o gênero, sabemos que pode ser concebido, a partir de textos, respectivamente, das antropólogas Marilyn Strathern e Henrietta Moore e da filósofa Judith Butler, como "distinção categorial"; "um idioma a partir do qual se ordenam diferenças de poder e/ou prestígio [...] e se constituem e qualificam sujeitos políticos"; "efeito performativo, materialidade e forma de regulação [...] que estrutura e opera formas corretas de estar no mundo, de estar em relação com os outros e de fabricar ou (des)fazer formas de vida" (apud Vianna; Lowenkron, 2017:23). Similarmente às tradições inventadas apontadas por Hobsbawm (2000) e definidas como práticas que buscam incutir valores e normas de comportamento por repetição, o gênero, para a filósofa política Judith Butler, é produzido por meio da repetição cotidiana de atos ou performances que, por sua vez, são encorajados ou desencorajados por normas que nos precedem (Butler, 2018).

Até a década de 1980, os entrelaçamentos entre nação e gênero, e seus processos de coconstituição e seus efeitos, não eram explorados. A literatura dominante sobre nações as considerava "zonas livres de gênero" (Walby, 2006, tradução própria), já que a nação seria resultado de processos discursivos, materiais, simbólicos e rituais que, supostamente, afetariam simbólica, material e psiquicamente - tanto homens quanto mulheres de maneira uniforme. Apesar de um dos mais conhecidos teóricos da nação argumentar que ela se tornou universal porque "assim como é esperado que todos tenham um gênero" (Anderson, 2006:5, tradução livre), é esperado que todos tenham, ou possam ter, ou devam ter, uma nação, e que, apesar de todas as desigualdades que existem dentro dela, a nação é pensada e imaginada como uma fraternidade (Anderson, 2006, grifo nosso), as implicações da coconstituição entre nação e gênero não foram exploradas por ele nem por seus colegas (homens) estudiosos da nação.

É significativo notar que o período histórico considerado por Hobsbawm como o apogeu do nacionalismo foi justamente marcado pela intensa participação de mulheres em movimentos $e$ organizações internacionais que lutavam pelo sufrágio feminino e pelo direito das mulheres de determinarem suas próprias nacionalidades (Sluga apud Walby, 2006). Além disso, em 1938 (45 anos antes das obras citadas de Anderson e Hobsbawm), a escritora Virginia Woolf, em seu ensaio Three Guineas, já tinha chamado atenção para o fato de que a posição de subordinação ocupada por mulheres ${ }^{4}$ na sociedade britânica, em termos de direitos, educação, renda e liberdade, gerava efeitos diferenciados nos corpos e mentes das mulheres no que dizia respeito às lealdades nacionais.

Woolf foi uma das primeiras feministas a problematizar o mito do soldado protetor, que supostamente travaria guerras em nome da proteção de mulheres e crianças, frágeis e indefesas, e que tanto ajuda a legitimar empreitadas militares e a superioridade masculina. Em um diálogo imaginado entre um homem e uma mulher britânicos, Woolf questiona:

\footnotetext{
4 As mulheres às quais Virginia Woolf se refere no ensaio são as filhas, irmãs e esposas de "homens educados", ou seja, daqueles homens que receberam educação universitária formal. A escritora tem pouco ou nada a dizer sobre as "filhas de homens não educados" e trabalhadoras domésticas britânicas, e menos ainda sobre mulheres colonizadas, negras ou indígenas. Podemos dizer que sua percepção fora condicionada pela posição que ocupava na sociedade britânica, situacionalidade esta que a escritora reconhecia.
} 
Quando ele diz [...] 'Estou lutando para proteger nosso país', buscando despertar nossas emoções patrióticas, ela se pergunta, "O que "nosso país" significa para mim enquanto uma forasteira?' [...] Se você insiste em lutar para me proteger, ou proteger o "nosso" país, que fique entendido entre nós, de forma sóbria e racional, que você está lutando [...] para obter benefícios que eu não compartilho e que provavelmente não irei compartilhar (Woolf, 2000:233, tradução própria ${ }^{5}$.

Foi neste ensaio que Woolf escreveu suas tão famosas frases: "como mulher, eu não possuo país [...] Como mulher, meu país é o mundo todo" (Woolf, 2000:234, tradução própria ${ }^{6}$ ).

É a partir da década de 1980 que as relações entre nação e gênero passam a ser exploradas com maior profundidade. Estudos iniciais, como os de Yuval-Davis e Anthias (1989) atentavam para os diferentes papéis desempenhados por mulheres em processos de construção nacionais: como reprodutoras biológicas, sociais e culturais da nação; como símbolos da nação; e como participantes ativas dos processos nacionais. Baseada no livro de Yuval-Davis e Anthias (1989), e em vários outros textos feministas, Peterson (1999) também identificou diversas formas, sobrepostas $e$ interativas, por meio dos quais mulheres são situadas na nação.

Primeiro, enquanto reprodutoras biológicas heterossexuais de membros da nação, as condições nas quais as mulheres podem ter filhos são reguladas. Tais regulações variam ao longo do tempo e do espaço, mas podem incluir políticas para estimular a taxa de natalidade de determinados grupos nacionais - em geral, daqueles que se conformam com a concepção dominante de nação - e para restringir a reprodução de grupos que não se conformam com a identidade nacional dominante, seja por meio de controles migratórios, expulsão, esterilização, ou até extermínio. Como mencionamos, o Presidente Erdoğan repetidamente exorta mulheres turcas a terem, pelo menos, três filhos (Daloglu, 2013; Turkish...,2016), não apenas para reproduzir a nação turca em sua vertente islâmica (Arat, 2010), mas porque, de acordo com o presidente, a mulher que prioriza a vida profissional e rejeita a maternidade abre mão de sua humanidade e nega sua feminilidade (Turkish...,2016).

Em segundo lugar, enquanto reprodutoras sociais e culturais da nação, às mulheres cabe incutir aparências, mentalidades e comportamentos considerados "adequados", seja no que tange gênero e sexualidade - ficando aqui sob incumbência das mulheres ensinar a divisão sexual do trabalho e como suas filhas, netas, sobrinhas, noras devem se portar — seja no que tange à nação: deve-se ensinar a língua "materna"; transmitir rituais e símbolos nacionais. Nesse papel, as próprias mulheres podem exercer $e$ punir mulheres jovens e/ou aquelas tidas como desviantes.

Em terceiro lugar, mulheres também aparecem como significantes (heterossexistas) de identidades de grupo, ou marcadores simbólicos da nação, por meio de metáforas da nação como mulher e da mulher como nação (Peterson, 1999). Talvez a figura de Marianne na França, eternizada no quadro de Delacroix, "A liberdade guiando o povo", de 1830, seja um dos significantes da mulher como nação mais conhecidos.

A nação muitas vezes é retratada como um corpo feminino que, em função disso, está sempre em risco de ser invadido e violado por outros homens (homens de outros grupos) e que, portanto, precisa ser defendida por meio das forças armadas e do sacrifício de seus cidadãos. Aqui, as ideias de honra, pureza, modéstia, castidade e respeitabilidade da mulher são fundamentais. Afinal, somente mulheres honradas e puras, de certa idade, orientação sexual e comportamento, podem reproduzir a nação. A nação como mulher nunca é imaginada como uma criança, uma mulher na menopausa, uma lésbica ou uma prostituta (Peterson, 1999). Em tempos de guerra, os corpos das mulheres podem se transformar em campos de batalha, com o estupro sendo usado como arma de guerra, para "desmoralizar" grupos rivais, que teriam suas mulheres, aqui entendidas como símbolos da nação, invadidas e violadas. Veremos como o medo da violação de corpos femininos,

\footnotetext{
5 No original: "When he says [...] "I am fighting to protect our country" and thus seeks to rouse her patriotic emotion, she will ask herself, "What does 'our country' mean to me an outsider?' [...] if you insist upon fighting to protect me, or 'our' country, let it be understood, soberly and rationally between us, that you are fighting [...] to procure benefits which I have not shared and probably will not share".

6 No original: "As a woman, I have no country [...] As a woman my country is the whole world".
} 
entendidos como símbolos da nação, se manifestou, por exemplo, na relação entre Mustafa Kemal Atatürk e sua filha adotiva Sabiha Gökçen.

Por fim, em determinados projetos de nação, as mulheres também podem ser representadas como agentes dos processos de construção nacional, participando da vida política, econômica e até militar, como foi (e é) o caso do projeto de nação kemalista. Em muitos casos, essa representação das mulheres como participantes ativas é instrumentalizada para apresentar tal nação como mais avançada em relação a nações concebidas como "tradicionais" no que diz respeito à igualdade de gênero e liberdade sexual. Veremos que o projeto de nação kemalista estimulou a participação de mulheres (turcas e seculares) na esfera pública (desde que dentro de certos limites) como forma de projetar a imagem de uma nação "moderna" e "civilizada", imagem esta importante em tempos de consolidação do Estado-nação em um sistema internacional hierárquico e eurocêntrico. Nesse processo, mulheres que não se encaixavam nesse perfil, em função de serem curdas, ou de usarem o véu islâmico, foram severamente afetadas, bem como mulheres turcas seculares que ousaram ultrapassar os limites estabelecidos.

Além disso, essa dicotomização hierárquica entre grupos com (suposta) igualdade de gênero $e$ liberdade sexual - turcos seculares - e grupos com (suposta) desigualdade de gênero e ausência de liberdade sexual - islâmicos e curdos - autoriza práticas de intervenção em áreas consideradas "atrasadas", como as regiões curdas; a restrição de direitos de mulheres islâmicas; e silenciamentos em relação às desigualdades, ausência de liberdades e violências que ocorrem em regiões supostamente mais avançadas, tais como a divisão desigual do poder, recursos econômicos e do trabalho, estupros, violência doméstica e assédios. É silenciado que até mesmo em nações ditas "modernas", como a turca kemalista, são estabelecidos limites para a "modernização" dos corpos e comportamentos das mulheres: podem votar, estudar, trabalhar, dirigir, sair de casa sozinhas, se candidatar a cargos públicos, ter direito à propriedade, à herança, ao divórcio, à guarda dos filhos, por exemplo, mas têm de respeitar determinadas regras de comportamento. Caso contrário, desigualdades, privação de liberdade e violências são justificadas e legitimadas.

Assim, parte da literatura feminista (além de Yuval-Davis; Anthias, 1989; Peterson, 1999; Jayawardena, 1986; Enloe, 1989; Tickner, 1996; Yuval-Davis, 1997; Walby, 2006) passou a questionar a concepção da nação como uma zona livre de gênero, mostrando como homens $e$ mulheres participam de formas diferentes dos projetos de construção de nações e como diferentes projetos de nação podem avançar diferentes relações de gênero. Questões de gênero e sexualidade; as relações entre homens e mulheres e entre mulheres; os graus apropriados de "modernização" de corpos e comportamentos; $e$ a interseccionalidade, passaram a ser vistos como irrevogavelmente imbricados com processos de produção e reprodução de nações. A partir desses estudos, a relação entre gênero e nação passou a ser pensada como uma via de mão dupla, na qual um constitui parcialmente o outro.

Tornou-se patente que as práticas discursivas $e$ materiais, simbólicas e rituais, que (re)produzem projetos dominantes de nação, gênero e sexualidade, tais como currículos escolares e livros-textos padronizados com versões oficiais da história; cerimônias públicas e feriados nacionais em datas comemorativas; monumentos públicos, museus e heróis nacionais; romances e jornais; discursos políticos, médicos e midiáticos; políticas públicas e política externa, dentre outros, distribuem de forma desigual entre homens e mulheres, etnias, classes e religióes, benefícios materiais, simbólicos e psíquicos. Por exemplo, tais heróis nacionais que figuram em livros de história, homenageados em cerimônias públicas, imortalizados em monumentos e romances e apresentados em museus são majoritariamente homens, e homens da etnia, nação, raça ou religião dominante - homens que lutaram em guerras de independência, homens que tiveram vitórias militares, homens que defenderam a pátria-mãe. Quando, excepcionalmente, mulheres também são alvo de homenagens e celebração - como é o caso, na Turquia, de Sabiha Gökçen e mulheres de terceira idade anônimas que teriam participado da Guerra de Independência e que figuram em monumentos públicos e livros-textos escolares - tais representações contribuem para reiterar o projeto de nação dominante, que marginaliza determinados segmentos populacionais.

Assim, nos processos de construção de nação, tanto o gênero quanto a sexualidade são peças cruciais dado que a reprodução da nação - tanto biológica quanto cultural e socialmente - é 
considerada fundamental. Dessa forma, o binarismo masculino-feminino; a dominância do masculino e a subordinação do feminino; a regulação de atividades produtivas e reprodutivas; o estabelecimento de esferas de atividades sociais generificadas (público e privado) que estruturam divisões desiguais de poder, recursos e trabalho; $e$ a heterossexualidade são marcados, privilegiados $e$ reproduzidos como naturais e desejáveis. Tais elementos foram naturalizados, normalizados $e$ institucionalizados na formação dos estados-nação europeus, no sistema internacional que constituído por eles e nas práticas coloniais que impuseram (Peterson, 1999).

Por fim, o uso de categorias essencializantes e universalizantes como "homem" e "mulher" precisa ser feito com cuidado, em função do risco de entrincheirar ainda mais tais categorias e de não nos atermos à intersecção de categorias relacionais de poder como gênero, sexualidade, nacionalidade, raça e classe (Peterson, 1999). Afinal, a categoria "mulheres" não é composta por um grupo de pessoas homogêneo e coeso, como enfatizamos ao longo do artigo. Vários marcadores de diferença afetam as experiências de mulheres e suas relações com outras mulheres $e$ homens. Algumas mulheres podem ter privilégios mantidos às custas de outras mulheres e homens. Além disso, embora concepções dominantes de nação, gênero e sexualidade nos precedam e atuem sobre nós, quando as reproduzimos, há sempre a possibilidade de resistência, desvios e desestabilização (Butler, 2018). Desse modo, gênero e sexualidade precisam ser abordados como categorias instáveis, polissêmicas e complexas.

Assim, podemos entender a nação como composta por sujeitos generificados e sexualizados cuja performatividade produz não apenas seu gênero e sexualidade, mas também a nação. Pela repetição de atos ou performances considerados aceitáveis e adequados, indivíduos ajudam a (re)produzir a concepção dominante de nação $e$ as concepções dominantes de gênero $e$ sexualidade, que sempre privilegiam alguns em detrimento de outros. Por sua vez, a nação também é generificada, mas de forma ambígua. Às vezes, é imaginada como uma fraternidade exclusivista, masculina, heterossexual $e$ aberta apenas àqueles que se conformam à concepção dominante de nação; muitas outras vezes, a nação é representada como uma mulher, virtuosa e casta, que precisa ser controlada, policiada, protegida e defendida por seus homens.

\section{"Modernas", mas até certo ponto: questões de gênero no projeto nacional kemalista}

O que intitulamos de projeto de nação dominante na Turquia corresponde aos esforços de produção de uma identidade turca a partir da fundação da República em 1923. O novo regime, liderado por Mustafa Kemal Atatürk de 1923 a 1938, promoveu uma série de reformas que visavam modificar o arcabouço jurídico-institucional estatal e também a aparência, comportamento $e$ mentalidade dos cidadãos turcos de acordo com parâmetros civilizacionais europeus, à época considerados superiores por grande parte dos líderes kemalistas. Fundada sobre os escombros do Império Otomano (1299-1922), desmembrado e invadido após perder a Primeira Guerra Mundial (1914-1918), a República que se instaurava imprimia continuidade ao processo de ocidentalização, modernização e secularização já iniciado no século XIX, durante o período de reformas chamado de Tanzimat (1839-1876) e no início do século XX, durante o governo dos chamados Jovens Turcos (1908-1918).

Tais reformas ocidentalizandes, conduzidas tanto pelo Império quanto pela República, podem ser entendidas como estratégias de sobrevivência em um sistema internacional hierárquico e eurocêntrico que frequentemente representava otomanos e turcos como atrasados, pré-modernos, bárbaros e inferiores e, assim, justificava intervenções nos afazeres domésticos e território do Império (Zarakol, 2010; Bilgin, 2009). Ou seja, o processo de identificação com a Europa/Ocidente, pelo menos em um primeiro momento, pode ser entendido como forma de garantir reconhecimento $e$, assim, evitar intervenções e adquirir direitos básicos, como soberania e não-intervenção.

As mulheres, nesse ímpeto modernizante e ocidentalizante do projeto nacional kemalista, foram mobilizadas de diversas formas: como símbolo da nação; reprodutoras biológicas, sociais e culturais e participantes ativas dos processos nacionais. Conceder direito às mulheres era visto pela elite kemalista como uma das formas de romper com as tradições islâmicas do Império Otomano, que se materializavam, no que diz respeito a questões de gênero, em práticas como casamentos arranjados, segregação dos sexos, uso do véu, poligamia e direito unilateral de divórcio, e orientar o 
país em direção ao Ocidente. Assim, direitos, aparências, comportamentos e mentalidades de mulheres eram tidos como elementos cruciais pela elite kemalista para distanciar o país de seu passado otomano e para aproximá-lo do Ocidente (Kandiyoti, 1989). De fato, a questão de gênero se tornou central nos debates entre diferentes projetos nacionais, no período entre a dissolução do Império e fundação da República, entre aqueles que preferiam uma Turquia ocidental, "moderna" e secular; aqueles que defendiam uma Turquia ainda alicerçada nas tradições otomanas $e$ islâmicas; $e$ aqueles que propunham algo no meio do caminho.

Islamistas, críticos das reformas do Tanzimat, e dos Jovens Turcos, que estenderam alguns direitos a não-muçulmanos e mulheres ${ }^{7}$, aceitavam a adoção de tecnologias e epistemologias ocidentais nos âmbitos econômicos e militares, mas estabeleciam limites para a "contaminação" ocidental: o direito de família, incluindo questões como divórcio, herança e guarda dos filhos, deveria voltar a seguir estritamente a Sharia (Kandiyoti, 1989:128). Correntes ferrenhamente próocidentalização, das quais faziam parte Mustafa Kemal Atatürk, defendiam a adoção de instituições, legislações e epistemologias ocidentais em todas as esferas: econômica, militar, política, cultural, familiar. Uma terceira corrente, da qual fazia parte um dos principais ideólogos do nacionalismo turco, Ziya Gökalp (1876-1924), considerava possível mesclar elementos ocidentais, islâmicos e turcos. Os escritos de Gökalp, inclusive no que tange à questão de gênero, influenciaram muitas das reformas do período Republicano.

Para Gökalp, era possível distinguir civilização de cultura e, assim, conciliar a civilização europeia, com seus aspectos científicos, tecnológicos, institucionais e legais; aspectos da civilização islâmica, desde que restritos à esfera privada; e elementos nacionais e culturais "autenticamente" turcos, ou seja, pré-islâmicos (Kadiyoti, 1989). A busca por esses elementos "autenticamente" turcos levou Gökalp a examinar relatos míticos, arqueológicos e antropológicos sobre turcos pré-islâmicos, que deram origem à sua obra Princípios do Turquismo. Nela, Gökalp argumentou que a moralidade familiar e sexual turca pré-islâmica incluía a igualdade entre homens e mulheres, nas esferas públicas e privada, e a monogamia; que as origens do feminismo turco poderiam ser encontradas em rituais e religiões xamânicas baseadas no poder sagrado das mulheres. Mulheres, inclusive, teriam sido excelentes guerreiras nessa era de outro "pré-islâmica" resgatada por Gökalp (Kandiyoti, 1989:141).

De acordo com Kandiyoti (1989), ao tornar a igualdade de gênero uma característica "autenticamente" turca, em vez de exclusivamente ocidental, Gökalp ajudava a tornar mais palatáveis as reformas ocidentalizantes promovidas no período republicano. Aqui, portanto, os entrelaçamentos entre gênero e nação se tornam particularmente visíveis. Ao tentar estabelecer uma linha de continuidade entre um passado turco pré-islâmico, um presente reformista e um futuro com igualdade de gênero, se tentava "naturalizar" e legitimar determinados cursos de ação em detrimento de outros, como um retorno à Sharia. De fato, a corrente ocidentalizante, no que diz respeito ao gênero, se tornou dominante. O código civil, baseado no suíço, adotado em 1926, proibiu a poligamia e concedeu direito de herança, divórcio e de custódia dos filhos igualitários. As mulheres ganharam direito ao voto em eleições locais em 1930 e em eleições nacionais em 1934 (Kandiyoti, 1989).

Em outros aspectos, o nacionalismo turco de Gökalp, que considerava a nação algo socialmente construído e, portanto, com fronteiras expansíveis, foi pervertido e mobilizado de forma essencialista e excludente. Na década de 1930, o Estado turco iniciou esforços para reescrever a história dos turcos dissociando-os o máximo do passado otomano - multiétnico, multirreligioso e multilinguístico - e buscando forjar uma identidade homogênea turca. Nesse afã foi fundada a Sociedade Nacional de História (Türk Tarih Kurumu), em 1931, com o intuito de "redescobrir" o passado pré-islâmico dos turcos e reescrever livros escolares (Altinay, 2004). A historiadora Afet Inan, uma das cofundadoras da Sociedade, e uma das cinco filhas adotivas de Atatürk, argumentou em seu livro "A Emancipação da Mulher Turca", publicado em 1962 (tal como Gökalp), que as mulheres turcas pré-islâmicas teriam um status mais igualitário em relação aos homens.

\footnotetext{
${ }^{7}$ No que diz respeito às mulheres, por exemplo, o Tanzimat concedeu direitos iguais de herança a filhos $e$ filhas (Kandiyoti, 1989:130). Já no período dos Jovens Turcos, o Código de Família de 1917 tornou ilegal casamentos sem consentimento e dificultou a poligamia, já que passou a exigir o consentimento da primeira esposa (Kandiyoti, 1989:137).
} 
As pesquisas empreendidas neste contexto também tinham o objetivo de "provar" que grupos como os curdos, os lazes e os circassianos tinham origens turcas, mas as tinham esquecido, e que, portanto, precisavam ser reeducados e relembrados de suas verdadeiras raízes (Altinay, 2004). As políticas de turquificação foram bastante violentas e incluíram a proibição de falar e aprender curdo (proibição essa somente relaxada no século XXI) e a opressão de vários movimentos de resistência curdos, incluindo a Operação Dersim de 1937-1938, sobre a qual falaremos mais à frente, na qual uma rebelião foi suprimida por meio de bombardeios aéreos que mataram cerca de 40.000 pessoas, principalmente curdos e alevis.

A historiografia oficial kemalista apresenta esse período de reformas como revolucionário para a vida das mulheres turcas. De acordo com essa narrativa, as reformas de Atatürk não só estabeleceram inúmeros direitos para as mulheres, como seriam das pioneiras no mundo nesse sentido. Além disso, tais direitos não teriam sido resultado das lutas de mulheres do país, mas produto inevitável do processo de ocidentalização e modernização e, portanto, entregues de bandeja.

No entanto, essa narrativa de "direitos das mulheres entregues de bandeja por líderes republicanos" passou a ser questionada, a partir da década de 1980, por autoras feministas turcas - como Deniz Kandiyoti, Ayse Gül Altinay e Yesim Arat, entre outras - que começaram a trazer à tona o histórico de lutas das mulheres turcas por direitos. Assim, pudemos saber que as primeiras vozes feministas começaram a ser ouvidas de forma inequívoca durante o período dos Jovens Turcos; que diferentes publicações femininas clamavam pelo direito à educação, ao voto, a sair nas ruas desacompanhadas e a trabalhar; que, quando defendiam o fim da poligamia, em geral tais publicações argumentavam que a prática era anti-higiênica, já que o ambiente ainda era muito conservador (Kandiyoti, 1989). Além disso, descobrimos que, em função da Primeira Guerra Mundial, e a consequente escassez de homens em determinados postos de trabalho, mulheres passaram a constituir a força de trabalho em maiores números (Kandiyoti, 1989) e que, nesse período, associações de mulheres para treinamento profissional foram fundadas. Entre 1908 e 1923, já existiam pelo menos quarenta organizações de mulheres e mais de vinte e sete publicações (Altinay, 2004).

\section{Sabiha Gokçen e violências interseccionais}

A narrativa kemalista reconhece - $e$ até glorifica - a participação ativa de mulheres na produção e reprodução da nação, incluindo em empreitadas militares, em determinados momentos históricos e em determinadas funções. A participação de mulheres na Guerra de Independência (das forças europeias que ocuparam o país depois da Primeira Guerra, 1919-1923), em particular, é celebrada em monumentos públicos e nos livros de história. Imagens de camponesas da Anatólia anônimas carregando e confeccionando munição para ajudar nos esforços de guerra são familiares para qualquer um que viva ou já tenha visitado à Turquia.

Sabiha Gökçen, que assim como a historiadora Afet Inan foi adotada por Atatürk, se tornou a primeira mulher turca a ser piloto de combate. Aos 24 anos, ela participou da Operação Dersim, de 1937, bombardeando áreas curdas-alevis ${ }^{8}$. A sua participação na repressão militar da insurreição em Dersim se tornou um dos símbolos do que as novas mulheres turcas poderiam alcançar: não apenas símbolos da nação, ou suas reprodutoras biológicas e sociais, mas agentes de sua construção.

A mobilização de Sabiha Gökçen nas narrativas kemalistas evidencia os entrelaçamentos complexos entre distintos marcadores de diferença, sejam eles nação, gênero, etnia, raça, religião, classe. Nota-se que a experiência de mulheres que prestavam serviços domésticos às mulheres modernas e profissionais da República não figuram nas narrativas kemalistas. Não sabemos quase

\footnotetext{
8 Alevismo é um ramo do Islã xiita que é praticado na Turquia e nos Balcãs tanto por turcos étnicos como por curdos. Relaciona-se ao alawismo da Síria, mas têm distinções do mesmo. Os curdos alevis da região de Dersim (renomeada de Tunceli - lê-se Tundjeli — pela República da Turquia), porém, consideram-se mais próximos do zoroastrismo do que do Islã. Tunceli é a única província turca com maioria alevi. Sakine Cansız, uma das fundadoras do PKK e assassinada em Paris em 2013, era curda-alevi nativa da região.
} 
nada, por exemplo, sobre a vida de Hatice Baci, que morou com Sabiha Gökçen em Eskişehir, durante seu treinamento na força aérea, supostamente para ajudar nas tarefas domésticas (Altinay, 2004). Além disso, na tentativa de consolidar como seus determinados significantes associados ao Ocidente - civilizado, moderno, secular - líderes kemalistas se engajavam em práticas de fronteira em relação às regiões curdas, representadas como mais atrasadas e pré-modernas no que diz respeito à igualdade de gênero, em função da existência de crimes de honra. Assim, igualdade de gênero foi $-e$ ainda é - mobilizada por determinados atores políticos turcos para justificar intervenções em áreas curdas.

Essa representação de atores políticos ocidentais (com os quais homens kemalistas tentam se identificar) como salvadores e protetores de mulheres orientais, representadas como vítimas passivas, não é inédita, é claro. Durante as empreitadas coloniais, o homem oriental (incluindo o turco!) foi, por vezes, efeminado, representado como homossexual, um ser com sexualidade desviante e pervertida. Por outras, como um troglodita bárbaro, sem limites em sua luxúria e violência contra mulheres (Loomba, 2005). As mulheres orientais, nessas narrativas, precisavam ser resgatadas por homens ocidentais, que seriam viris (não homossexuais), mas corteses (não trogloditas e bárbaros).

Assim, dentre as múltiplas masculinidades possíveis, emergia uma forma de masculinidade "correta", atribuída aos homens ocidentais: nem "contaminada" por atributos associados à feminilidade, como emoção, fragilidade, irracionalidade e passividade; tampouco "hipermasculina", envolvendo elementos como agressividade excessiva, violência e barbarismo (Bilgiç, 2016). Na narrativa kemalista sobre os curdos, essa histórica narrativa colonial, que justifica políticas "salvacionistas" ou "protetivas", foi atualizada e recontextualizada: a proteção de mulheres curdas foi mobilizada como justificativa para intervenções e o Estado turco passou a ser representado como salvador/protetor que desempenha a masculinidade 'correta', associada ao Ocidente.

Tal narrativa do Estado-nação turco protetor, dotado de masculinidade adequada, pode ser desestabilizada quando lembramos das 40.000 pessoas mortas na Operação Dersim, algumas em função de bombas jogadas pela própria Sabiha Gökçen (Altinay, 2004); de guerrilheiras curdas que pegam em armas contra o Estado turco, desafiando representações que enfatizam tanto a passividade das curdas quanto a benevolência dos turcos; e que o próprio Estado-nação turco, no presente e no passado, foi frequentemente feminizado ou hipermasculinizado em narrativas ocidentais (Bilgiç, 2016:48), que, assim, justificavam intervenções em territórios turcos.

No entanto, apesar da impossibilidade de estabilização, tais atualizações de narrativas coloniais salvacionistas e protetivas persistem na Turquia. A falta de liberdade sexual e a desigualdade de gênero ainda são invocadas como justificativas para intervenções turcas em áreas curdas e para legitimar políticas que restringem determinadas manifestações de religiosidade, como o uso do véu em determinados espaços.

Um dos principais marcadores da diferença entre os projetos de nação kemalista $e$ o islâmico, do AKP e de partidos predecessores, é o uso do véu. Se para aderentes do projeto kemalista o véu é um símbolo de opressão e atraso, ou até mesmo de traição ao projeto de Atatürk (Savci, 2016) para determinados quadros do governo AKP, o véu é um requerimento do Islã (Arat, 2010). No caso do véu, portanto, os corpos de mulheres se tornam os campos de batalha entre projetos de nação supostamente rivais, mas que compartilham uma série de premissas. Uma delas, é claro é o próprio controle do corpo feminino, que é encorajado a se revelar ou a se cobrir de acordo com os ditames ora da modernidade ocidental, ora de preceitos religiosos.

O uso do véu foi oficialmente banido em universidades públicas em 1987, mas o banimento só passou a ser de fato implementado a partir a partir de 1997, quando forças policiais e de segurança das universidades passaram a retirar estudantes com véu dos campi (Savci, 2016). Com a eleição do AKP em 2002, essa questão se tornou ainda mais premente no debate público. É instrutivo notar que, em alguns desses debates, ativistas muçulmanas que defendiam o uso de véu em universidades, e apenas elas, eram requisitadas a provar que apoiavam direitos $e$ liberdades LGBTQIA+; caso contrário, argumentava-se que não seriam merecedoras de direitos democráticos e liberdades fundamentais (Savci, 2016). Nesses casos, a visão da homossexualidade se tornou prova-dos-nove da modernidade (Savci, 2016) e a condição ser considerado digno de direitos e 
liberdades. Mais uma vez, a liberdade sexual (ou a ausência dela) foi mobilizada na Turquia para justificar restrições e direitos para alguns grupos sociais (nesse caso, mulheres que usam o véu).

\section{A castidade e os limites da igualdade e da liberdade}

A história de Sabiha Gökçen, além de ajudar a expor as violências cometidas contra, por e entre mulheres, ao longo de eixos como classe, etnia e religião, também evidencia o uso das metáforas da mulher como nação $e$ da nação como mulher $e$ os limites impostos à igualdade $e$ à liberdade femininas no projeto nacional kemalista. Como relata Sabiha em sua autobiografia, antes de voar para Dersim, Atatürk teria lhe dado uma arma e dito:

Você não deve esquecer que você é uma garota. A sua missão é difícil e você irá encontrar com hordas de homens alucinados [os curdos]. Se algo acontecer que coloque sua honra em risco, não hesite em usar essa pistola para matar outros ou para se matar (apud Altinay, 2004:39).

Ou seja, quando Sabiha partiu para Dersim, ela tinha a dupla missão de proteger sua nação e sua honra que, nesse caso, eram fundidas. Ser violada por homens de outro grupo (os curdos), seria pior do que a morte.

Assim, fica claro que, em geral, castidade, pureza e modéstia são atributos considerados essenciais em narrativas nacionalistas, já que, como vimos, apenas mulheres castas e puras estariam aptas a reproduzir biologicamente a nação. No caso do nacionalismo kemalista, que admite papéis mais variados para as mulheres, a preocupação com a castidade revela os limites da igualdade de gênero e liberdade sexual encorajadas por esse projeto. Até mesmo Ziya Gökalp, que recuperou o passado guerreiro das turcas pré-islâmica, enfatizava que, além de corajosas, as mulheres turcas eram particularmente conhecidas pela sua castidade e honra (Kandiyoti, 1989). Sabiha Gökçen, portanto, encarnava os atributos da bravura e da castidade, que se manifestavam em mulheres turcas desde a era pré-islâmica, e que tinham sido particularmente visíveis durante a Guerra de Independência (Altinay, 2004). Desse modo, o grau apropriado e suficiente de modernização para os corpos e comportamentos das mulheres foi definido por homens (Durakbasa; llyasoglu, 2001). Mulheres poderiam participar da vida pública, até mesmo em campanhas militares, mas teriam de respeitar as regras de castidade e honra.

Durakbasa e Ilyasoglu (2001), integrantes de um projeto da Biblioteca das Mulheres, em Istambul, de recuperação da história oral de mulheres turcas, realizaram entrevistas com diversas mulheres consideradas agentes da modernização kemalista: mulheres instruídas e profissionais como professoras e médicas, ou esposas de funcionários públicos, diplomatas ou militares fundadores da república. Os relatos trazidos por elas evidenciam as tensões sentidas e negociadas por mulheres autorizadas a interagir com homens fora de seu círculo familiar e a utilizar vestuário associado ao Ocidente e à modernidade. Agora que participavam da esfera pública, às mulheres era atribuída a responsabilidade pela conduta social "apropriada" e "civilizada", ou seja, aquela que evitava atrair olhares lascivos ou causar ciúmes em seus maridos (Durakbasa; Ilyasoglu, 2001).

Ou seja, a "nova mulher turca" seria "moderna, mas virtuosa" - essa mulher estaria entre a modernidade e a tradição (Durakbasa; llyasoglu, 2001:196). As mulheres turcas continuavam a ser vistas, por um lado, como as procriadoras e educadoras das novas gerações, as "mães esclarecidas da nação" (Durakbasa; Ilyasoglu, 2001:195) e, por outro, como participantes ativas do projeto de construção nacional, como profissionais e até militares. Ao mesmo tempo, a aparência e o comportamento dessas mulheres deveriam ser controlados e contidos dentro de certos limites.

Dessa forma, podemos entender que as fronteiras entre o projeto de nação kemalista $e$ o projeto de nação do $\mathrm{AKP}$, no que tange à questão de gênero, são menos rígidas do que em geral se pressupõe. Apesar de muitas vezes ser retratado, não sem razão, como responsável por um grande retrocesso, o governo do AKP apresenta uma série de continuidades em relação aos governos kemalistas anteriores. A aliança tácita entre os aderentes desses dois projetos de nação possibilitou políticas violentas, excludentes e restritivas direcionadas a curdos e curdas, mulheres muçulmanas e mulheres seculares. Dado que os alvos das políticas de crueldade estatais e sociais da Turquia são plurais, as resistências a essas políticas (tema próxima e última seção) também o são. 


\section{Disputas e alianças na luta contra a crueldade}

Organizações de mulheres, movimentos feministas - seculares, islâmicos e curdos - e grupos LGBTQ na Turquia nem sempre estão de acordo e, muitas vezes, entram em disputa. A partir da década de 1990, movimentos feministas de origem muçulmana e curda passam a ganhar mais visibilidade e a acusar o feminismo turco mainstream de ser etnocêntrico e elitista, formado por mulheres turcas de classe média, dos grandes centros urbanos, educadas e ocidentalizadas $e$ excludente de mulheres de contextos econômicos, sociais, étnicos e religiosos diferentes (Diner; Toktas, 2010). Talvez a epítome desse feminismo mainstream violento e excludente (além de Sabiha Gökçen, é claro) seja Tansu Çiller, a única mulher primeira-ministra da Turquia, que é tida como uma espécie de Margareth Thatcher do país, tanto por suas políticas neoliberais, quanto pela mão de ferro com que lidou com os curdos, a quem se referia como "turcos da montanha". Durante seu governo (1993-1996), ela presidiu um escalonamento da violência entre o estado turco e o $\mathrm{PKK}^{9}$ (Tansu..., 1996).

Nesse contexto de contestação do feminismo mainstream, feministas curdas mostraram que as mulheres desse grupo étnico são sujeitas a dois tipos de opressão: relações desiguais de gênero em sociedades curdas, que autorizariam, dentre outras coisas, crimes de honra, violência doméstica e casamentos arranjados de menores de idade, e por parte do Estado turco e suas políticas de turquificação e uso da força militar e policial em áreas curdas (Diner; Toktas, 2010). A curda-alevi Sakine Cansiz (1958-2013), natural de Dersim/Tunceli, talvez seja o grande nome dessa questão, sendo uma das fundadoras em 1978 do PKK e de seu esquadrão de mulheres nos anos $1990^{10}$. Feministas islâmicas, por sua vez, mostraram que também estão sujeitas a dois tipos de opressão: por parte do Estado turco, com suas políticas de secularização e restrição de liberdades religiosas, $e$ por parte de homens muçulmanos que defendem a segregação dos sexos e a restrição das mulheres à esfera doméstica (Diner; Toktas, 2010).

No entanto, essa divisão tripartite entre feministas seculares, curdas e islâmicas, $e$ as narrativas sobre opressão patriarcal curda e islâmica também não são inabaláveis. Por exemplo, a questão da igualdade e representatividade de gênero tornou-se ponto importante da ideologia de Abdullah Öcalan, fundador do PKK, após sua prisão em 1999, no chamado Confederalismo Democrático, e têm papel importante na plataforma do Partido Democrático dos Povos (HDP, em turco), criado em 2012. Esse último trabalha com um sistema de coliderança do partido, que sempre inclui um homem e uma mulher. De 2014 a 2017 a jornalista turca Figen Yüksekdağ ocupou o espaço de liderança junto ao advogado curdo Selahattin Demirtas. Essa atenção às questões de gênero por parte de lideranças curdas complexifica a narrativa de que as intervenções turcas em áreas curdas se legitimam em parte em função do atraso curdo na questão de gênero.

Além disso, existem laços de solidariedade entre feministas seculares e islâmicas que denunciam o controle dos corpos e do comportamento de mulheres, seja esse controle justificado em nome da modernidade e do secularismo ou em nome de tradições religiosas (Arat, 2010). Desde 1998, todas as organizações do país que combatem a violência contra a mulher se encontram anualmente para discutir a formulação de políticas públicas (Diner; Toktas, 2010). Desde 2003, as marchas em Taksim, Istambul, no Dia Internacional da Mulher, reúnem mulheres curdas, muçulmanas e seculares que protestam contra desigualdade econômica, brutalidade policial $e$ violência doméstica (Tremblay, 2019). Em alguns casos, essas alianças vão além de grupos feministas, e incluem também pessoas queer, gays, lésbicas e transgêneros (Butler, 2018).

Em outras instâncias, os elos de solidariedade são abrangentes o suficiente para unir diversos alvos da violência estatal e social, incluindo grupos feministas, seculares e islâmicos, LGBTQIA+e curdos, em oposição à crueldade estatal e social na Turquia (Savci, 2016). Por exemplo, no contexto do debate sobre a proibição do uso do véu, três mulheres muçulmanas, Hilal Kaplan,

\footnotetext{
9 O PKK (Partido dos Trabalhadores do Curdistão, em curdo) foi criado em 1978 por Abdullah Öcalan para lutar por mais direitos culturais e políticos para curdos da Turquia. Desde a década de 1980, o grupo vem se engajando em uma luta armada contra o estado turco.

${ }^{10} \mathrm{O}$ documentário "Curdistão: garotas em guerra" permite vislumbres da biografia dessa ativista curda, assassinada em Paris, em 2013 [https:/www.youtube.com/watch?v=SMwFY3SoBUY - acesso em: 13 jul. 2021].
} 
Havva Yilmaz e Neslihan Akbulut, lançaram uma petição criticando as desigualdades, injustiças e violências perpetradas pelo estado turco, incluindo a proibição do uso do véu e o tratamento concedido a curdos e alevis (Savci, 2016). Uma delas, então colunista do jornal Taraf, ligado ao Movimento Gulën, argumentou que a homossexualidade, apesar de ser vista como um pecado no Islá, não é vista como um pecado mais sério do que consumir bebidas alcoólicas e fumar e, portanto, nenhuma crueldade a homossexuais deveria ser tolerada (Savci, 2016:176). Assim, fica claro que, apesar dos embates, existe espaço para a negociação e a confecção de elos de solidariedade entre diversos grupos de mulheres, LGBTQIA+, curdos e alevis na luta contra a crueldade, violência $e$ injustiças perpetradas pelo estado turco, seja ele ocupado por aqueles que defendem um projeto de nação kemalista ou islamista.

\section{Considerações finais}

Este artigo teve como objetivo discutir os entrelaçamentos entre gênero e nação em geral, $e$ na Turquia contemporânea em particular. Nosso principal intuito foi evidenciar que as fronteiras entre diversos grupos políticos e sociais na Turquia - entre projetos de nação kemalista, islamista e curdo; entre feminismos seculares, islâmicos e curdos; entre movimentos feministas e grupos LGBTQIA + - não são tão estanques quanto se imagina. Para além das óbvias e aparentes disputas, esses grupos possuem vários pontos de contato e são capazes de forjar alianças, tácitas ou deliberadas, tanto para praticar políticas de crueldade quanto para resisti-las.

Assim, os projetos de nação kemalista e islamista, apesar de usualmente serem apresentados como a antítese um do outro, compartilham a ideia de que os corpos e os comportamentos das mulheres (e homens) devem estar sujeitos à regulação $e$ justificam práticas intervencionistas $e$ restritivas em direção a alguns grupos políticos e sociais a partir da mobilização de questões de gênero e de sexualidade. Atores políticos kemalistas defendem a proibição do uso do véu e a intervenção militar em áreas curdas em nome da emancipação feminina e da liberdade sexual; atores políticos do AKP defendem o uso do véu em nome da liberdade religiosa, de movimento, de envolvimento da esfera pública e da (liberdade de) assédio sexual; ambos enxergam a honra das mulheres como extensão da honra da nação e promovem políticas de crueldade contra homens e mulheres. De forma similar, as resistências a esses projetos de nação violentos e excludentes também são capazes de se articular, muitas vezes de forma deliberada.

Além disso, buscamos mostrar que, assim como as fronteiras entre grupos domésticos na Turquia são porosas, as fronteiras entre a Turquia e o internacional também não são impermeáveis. Ao longo do histórico de interações da Turquia e seu predecessor, o Império Otomano, com o Ocidente (seja ele entendido como a Europa, a União Europeia ou os Estados Unidos), o país foi ambiguamente feminilizado e hipermasculinizado, e essa generificação serviu como justificativa para intervenções de países ocidentais na Turquia. Muitas vezes, atores políticos turcos, ao se identificarem com o Ocidente, reproduzem discursos salvacionistas e protetivos que autorizam práticas violentas e excludentes internamente. Dessa forma, concluímos que o entrelaçamento entre gênero e nação é complexo, ambíguo e multifacetado e que as distribuições desiguais de feminilidades e masculinidades autorizam tanto práticas de crueldade e quanto de resistências a elas.

\section{Referências bibliográficas}

ALTINAY, Ayse Gül. The Myth of the Military Nation - Militarism, Gender and Education in Turkey. Nova Iorque, Palgrave MacMillan, 2004.

ANDERSON, Benedict. Imagined Communities: Reflections on the Originand Spread of Nationalism. Londres, Verso, 2006 [1983].

ARAT, Yesim. Religion, Politics and Gender Equality in Turkey: implications of a democratic paradox? Third World Quarterly31(6), 2010, pp.869-884.

BILGIÇ, Ali. Turkey, Power and the West - Gendered International Relations and Foreign Policy. Londres, I.B. Tauris, 2016. 
BILGIN, Pinar. Securing Turkey through Western-oriented foreign policy. New Perspectives on Turkey 40, 2009, pp.102-125.

BUTLER, Judith. Corpos em aliança e a politica das ruas. Rio de Janeira, Civilização Brasileira, 2018.

BUTLER, Judith. Sexual Politics, torture and secular time. The British Journal of Sociology59(1), 2008.

CAMPBELL, David. Writing Security: United States Foreign Policy and the Politics of Identity. Minneapolis, University of Minnesota Press.

CASARÕES, Guilherme. Brasil y Turquía: hoy socios ¿aliados mañana? In: GONZALEZ, Ariel Sebastián; FEREZ, Manuel (org.). Turquía-América Latina y el Caribe: una asociación emergente. Buenos Aires/Istambul, Bahçeşehir Universitesi, 2016, pp.213-240.

COMISSÃO EUROPEIA. Turkey 2018 Report [https://www.ab.gov.tr/siteimages/kapbtablolar/20180417turkey-report.pdf - acesso em: 16 jul 2019].

DALOGLU, Tülin. Erdogan Insists on Demanding Three Children. Al-Monitor, 3 Aug 2013 [https://www.almonitor.com/pulse/tr/originals/2013/08/erdogan-asks-turks-to-have-three-children.html - acesso em: 15 jul 2019].

DINER, Cagla; TOKTAS, Sule. Waves of feminism in Turkey: Kemalist, Islamist and Kurdish women's movements in an era of globalization. Journal of Balkan and Near Eastern Studies 12(1), 2010, pp.41-57.

DUMOVICH, Liza. Pious creativity: Negotiating Hizmet in South America after July 2016. Politics, Religion \& Ideology, v. 19, Issue 1, 2018, pp.81-94 .

DURAKBASA, Ayse; ILYASOGLU, Aynur. Formation of Gender Identities in Republican Turkey and Women's Narratives as Transmitters of 'Hersory' of Modernization. Journal of Social History 35 (1), 2001, pp.195-203.

ENLOE, Cynthia. Bananas, Beaches and Bases: Making Feminist Sense of International Relations. Londres, Pandora, 1989.

FINDLEY, Carter Vaughn. Turkey, Islam, Nationalism and Modernity. A History, 1789-2007. Yale University Press, 2010.

FISHER-ONAR, Nora; MÜFTÜLER-BAÇ, Meltem. The adultery and headscarf debates in Turkey: Fusing "EU-niversal" and "alternative" modernities? Women's Studies International Forum 34, 2011, pp.378-389.

GÜNEŞ-AYATA, Ayse; DOĞANGÜN, Gökten. Gender Politics of the AKP: Restoration of a Religioconservative Gender Climate. Journal of Balkan and Near Eastern Studies, v. 19, Issue 6, 2017, pp.610627.

GÜZELDERE, Ekrem Eddy. Brazil-Turkey: two emerging powers intensify relations. Brasilia, FUNAG, 2018.

HOBSBAWM, Eric; RANGER, Terence (org.) The Invention of Traditions. Cambridge, Cambridge University Press, 2000 [1983].

JAYAWARDENA, Kumari. Feminism and nationalism in the Third World. Londres, Zed Books, 1986.

KANDIYOTI, Deniz. Women and the Turkish State: Political actors or Symbolic Pawns? In: YUVAL-DAVIS, Nira; ANTHIAS, Floya (org.). Women-Nation-State. Londres, The Macmillan Press, 1989, pp.126-149.

LARAZOU, Elena; NASCIMENTO, Milan Yan. ¿Estratégia o visión? La cooperación emergente entre Brasil y Turquía. In: GONZALEZ, Ariel Sebastián; FEREZ, Manuel (org.). Turquía-América Latina y el Caribe: una asociación emergente. Buenos Aires/Istambul, Bahçeşehir Universitesi, 2016, pp.193-212.

LOOMBA, Ania. Colonialism/Postcolonialism. London, Routledge, 2005.

LOWEN, Mark. Women challenge Turkey traditions for right to work. BBC News, 1 Mar 2018 [https://www.bbc.com/news/world-europe-43197642 - acesso em: 16 jul 2019].

MAYER, Tamar. Gender ironies of nationalism: setting the stage. In: MAYER, Tamar (org.). Gender Ironies of Nationalism: Sexing the Nation. Londres, Routledge, 2000, pp.1-25.

MELLO, Patrícia Campos. Lua de Mel em Kobane. São Paulo, Companhia das Letras, 2017.

NAÇÕES UNIDAS - UNITED NATIONS DEVELOPMENT PROGRAM. Human Development Reports Turkey [http://hdr.undp.org/en/countries/profiles/TUR - acesso em: 16 jul 2019]. 
NARLI, Nilüfer; TREVISANY, Leonardo Nelmi. Las nuevas realidades políticas de la democratización y las relaciones civiles-militares en Turquía y Brasil: similitudes y diferencias. In: GONZALEZ, Ariel Sebastián; FEREZ, Manuel (org.). Turquía-América Latina y el Caribe: una asociación emergente. Buenos Aires/Istambul, Bahçeşehir Universitesi, 2016, pp.305-338.

OLIVEIRA, Marcos Aurelio Guedes de; SANTOS, Deijenane Gomes dos. Brazil, the United States and the Tehran Declaration. Rev. bras. polít. int., v. 61, n. 1, Brasilia, 2018, e009.

PETERSON, V. Spike. Political Identities/Nationalism as Heterosexism. International Feminist Journal of Politics 1 (1), 1999, pp.34-65.

SANDRIN, Paula. Fazendo ou desfazendo a União Europeia enquanto potência global: uma análise sobre potenciais impactos da Turquia na política externa e de segurança comum do bloco. Contexto Internacional (on-line), v. 37, 2015, pp.469-507.

SANDRIN, Paula. Turquia e União Europeia: explicando uma relação resiliente. In: Fundação Konrad Adenauer (org.). A União Europeia alargada em tempos de novos desafios. v. 4, 2014, pp.97-107.

SAVCI, Evren. Subjects of Rights and Subjects of Cruelty: The Production of an Islamic Backlash Against Homosexuality in Turkey. In: ORLOFF, Ann Shola; RAY, Raka; SAVCI, Evren. Perverse Politics? Feminism, Anti-Imperialism, Multiplicity. Political Power and Social Theory Book Series, v. 30. Bingley, Emerald Group Publishing, 2016, pp.159-186.

SOCHACZEWSKI, Monique. De Atatürk a Erdoğan: A República da Turquia em três tempos. Malala, 6(9), 2018, pp.70-90.

STAVRAKAKIS, Yannis. Enjoying the Nation: A Success Story? In: The Lacanian Left. Edimburgo, Edinburgh University Press, 2007, pp.189-211.

TANSU Ciller. New Internationalist, 5 Jan 1996 [https://newint.org/features/1996/01/05/tansu - acesso em: 17 jul 2019].

TEKIN, Segâh. Brezilya'nın dişpolitikası: gelenekvedeğisim. Tese (Doutorado em Relações Internacionais), Selçuk Üniversitesy, Konya, 2016.

TICKNER, J. Ann. Identity in International Relations Theory: Feminist Perspectives. In: LAPID, Yosef; KRATOCHWIL, F. The Return of Culture and Identity in IR Theory. Boulder, Lynne Rienner Publishers, 1996, pp.147-162.

TREMBLAY, Pinar. Has misogyny become official state policy in Turkey? [https://www.almonitor.com/pulse/originals/2019/03/turkey-why-is-erdogan-alienating-women.html\#ixzz5tnrVHD1V acesso em: 15 jul 2019].

TURKISH president says childless women are "deficient, incomplete". The Guardian, 6 Jun 2016 [https://www.theguardian.com/world/2016/jun/06/turkish-president-erdogan-childless-women-deficientincomplete - acesso em: 15 jul 2019].

VIANNA, Adrianna; LOWENKRON, Laura. O duplo fazer do gênero e do Estado: interconexões, materialidades e linguagens. cadernos pagu (51), Campinas-SP, Núcleo de Estudos de GêneroPagu/Unicamp, 2017, e175101.

WALBY, Sylvia. Gender Approaches to Nations and Nationalism. In: DELANTY, Gerard; KRISHAN, Kumar (org.). The SAGE Handbook of Nations and Nationalism. Thousand Oaks, CA, SAGE Publications, 2006, pp.118-128.

WOOLF, Virginia. A Room of One's Own/Three Guineas. Londres, Penguin Books, 2000 [1938].

YUVAL-DAVIS. Gender and Nation. Londres, Sage, 1997.

YUVAL-DAVIS, Nira; ANTHIAS, Floya; Yuval-Davis, Nira (org.). Women-Nation-State. Londres, The Macmillan Press, 1989.

ZARAKOL, Ayse. After Defeat: Howthe East Learned to Live with the West. Cambridge, Cambridge University Press, 2011. 